\title{
Role of Terminal Groups in Aromatic Molecules on the Growth of $\mathrm{Al}_{2} \mathrm{O}_{3^{-}}$ Based Hybrid Materials
}

\author{
Arbresha Muriqi ${ }^{1}$, Maarit Karppinen ${ }^{2}$ and Michael Nolan ${ }^{1}$ \\ 1: Tyndall National Institute, Lee Maltings Complex Dyke Parade, Cork, Cork, T12 R5CP, Ireland \\ 2: Department of Chemistry and Materials Science, Aalto University, FI-00076 Espoo, Finland \\ ORCID: AM: 0000-0002-2392-0278, MK: 0000-0003-1091-1169, MN: 0000-0002-5224-8580
}

\section{Michael.nolan@tyndall.ie}

\begin{abstract}
Hybrid materials composed of organic and inorganic components offer the opportunity to develop interesting materials with well-controlled properties. Molecular Layer Deposition (MLD) is a suitable thin film deposition technique for the controlled growth of thin, conformal hybrid films. Despite the great interest in these materials, a detailed understanding of the atomistic mechanism of MLD film growth is still lacking. This paper presents a first principles investigation of the detailed mechanism of the growth of hybrid organic-inorganic thin films of aluminium oxide and aromatic molecules with different terminal groups deposited by MLD. We investigate the chemistry of the MLD process between the post-TMA pulse methyl-terminated $\mathrm{Al}_{2} \mathrm{O}_{3}$ surface and the homo- or hetero- bifunctional aromatic compounds with hydroxy $(\mathrm{OH})$ and/or amino $\left(\mathrm{NH}_{2}\right)$ terminal groups: hydroquinone (HQ), pphenylenediamine (PD) and 4-aminophenol (AP). Double reactions of aromatic molecules with the alumina surface are also explored. We show that all aromatic precursor molecules bind favourably to the methyl terminated $\mathrm{Al}_{2} \mathrm{O}_{3}$, via formation of $\mathrm{Al}-\mathrm{O}$ and $\mathrm{Al}-\mathrm{N}$ bonds and $\mathrm{CH}_{4}$ elimination. While reaction energetics suggest a higher reactivity of the OH group with TMA in comparison to the $\mathrm{NH}_{2}$ group, which could enable the double reaction phenomenon for HQ we propose that the upright configuration will be present so that the organic molecules are self-assembled in an upright configuration, which leads to thicker hybrid films. Interactions between the methyl-terminated $\mathrm{Al}_{2} \mathrm{O}_{3}$ with substituted phenyls are investigated to examine the influence of phenyl functionalisation on the chemistry of the terminal groups. Reaction energetics show that phenyl functionalization actually promotes an upright configuration of the molecule, which leads to thicker and more flexible films, as well as tuning the properties of the aromatic components of the hybrid films. We also investigate the interactions between methyl-terminated $\mathrm{Al}_{2} \mathrm{O}_{3}$ with new possible MLD organic precursors, hydroquinone bis(2-hydroxyethyl)ether and 1,1'-biphenyl-4,4'-diamine. DFT shows that both aromatic molecules react favourably with TMA and are worthy of further experimental investigation.
\end{abstract}

\section{Introduction}

The development of hybrid inorganic-organic materials with well-controlled properties is important for the future of nanoscale films and coatings with tunable properties for use in many technologies. Hybrid materials display features that combine the advantages of the individual materials and can add functionalities that are not present in the individual inorganic or organic components. $[1,2,3,4,5]$ The inorganic components incorporated in hybrid materials contribute to their excellent dielectric and magnetic features, including electrical resistivity, good thermal stability, and enhanced chemical stability. The organic compounds provide structural flexibility, efficient luminescence, photoconductivity, tunable electronic properties, and low density.[6] The combination of the advantages of both components makes hybrid materials suitable candidates in many technologies, such as protective coatings, [7] sensors,[8], catalysis, [9] optical devices, [10] etc. 
Atomic layer deposition (ALD) is a thin film deposition technique based on sequential and self-limiting surface reactions, and has proven to be a leading technique to deposit conformal, smooth and pinhole free inorganic films. $[11,12,13,14]$ A very similar technique, molecular layer deposition (MLD) is used to produce a wide spectrum of a new class of hybrid inorganic-organic films by controlling the thickness of each individual organic and inorganic layer. Such hybrid materials fabricated using MLD can display tuneable thermal stability and excellent mechanical properties at the atomic and molecular level. $[3,5,15,16,17,18]$

Metalcones are metal alkoxide films that are formed from organometallic precursors and organic alcohols.[3,4,5,19,20] The first reported MLD-grown films were aluminum alkoxide films known as "alucone"[21] and thereafter many more alucones were developed.[22,23] Later, many other metalcone groups were reported such as on zincone,[24,25,26] titanicone,[27,28,29] hafnicone,[30] vanadicone, [31] magnesicone, [32] and metal-based polymers.[33,34]

Much has been done in developing different MLD processes [22,24,27,30,31,32,33] but much less is known about the important steps in MLD film growth. To better understand the deposition process and growth mechanism of hybrid films at molecular level, a combination of experimental data and theoretical data is needed. Density functional theory (DFT) has proven to be a powerful tool that allows us to explore and understand the reactions between the organometallic precursors and organic molecules that lead to the formation of metalcones and to address aspects of MLD experiments. [32,35,36,37]

In ref 32 DFT calculations were used to explore the growth mechanism of magnesium containing hybrid films known as "magnesicone" through the reaction of ethylene glycol (EG) and glycerol (GL) at $\mathrm{MgCp}$-terminated $\mathrm{MgO}$ as a model system. This study shows that while the ligand elimination process is favourable for both organic molecules, EG prefers to orient in a flat configuration and interacts at the $\mathrm{MgO}$ surface and GL species prefer to lie in an upright position. This yields thicker GL-based films, consistent with experiment. Furthermore, DFT was used to investigate the molecular mechanism of the growth of aluminium alkoxides grown using trimethylaluminum (TMA) and EG or GL. This work shows that EG and GL can lie flat and create the so-called double reactions through the reaction of the two terminal hydroxyl groups with the surface fragments. This phenomenon removes active hydroxyl sites for EG. For GL the third hydroxyl group is available and growth can proceed. DFT studies in ref 32 and 37 support experimental findings regarding the differences in magnesicone and alucone films grown with EG and GL.[32][38]

The double reaction phenomenon of organic molecules in hybrid film growth is a common issue that will reduce the number of reactive groups in the surface, depress the film growth rate and give less flexible films.[29,31,32,38,39] Many metal-organic films have been deposited by using phenyl-based organic precursors.[40,41,42,43,44,45,46,47] Because of their stiff backbone, such molecules have been considered as a possible solution to reduce the number of double reactions that hinder the film growth. In addition, aromatic molecules are of high interest as they are easy to work with, stable in air, volatile when heated and thermally stable. Aromatic molecules are also very desirable since the resulting films are relatively, smooth, amorphous and stable in air. Furthermore, conjugated organics can serve as electrical conductors, e.g. hydroquinone ( $\left.\mathrm{HQ}, \mathrm{OH}-\mathrm{C}_{6} \mathrm{H}_{4}-\mathrm{OH}\right)$ has been shown to improve the conductivity of $\mathrm{ZnO}$ for particular $\mathrm{ZnO}: \mathrm{HQ}$ ratios.[42] In another study, ALD and MLD were combined to create hybrid superlattice structures consisting of single layers of HQ within the (Zn,Al)O framework to enhance the material's thermoelectric properties. It was shown that the addition of HQ can hinder the propagation of phonons through the structure and thus lower thermal conductivity.[43]

In ref 41 aromatic carboxylic acids such as 1,2-benzene dicarboxylic acid, 1,3-benzene dicarboxylic acid, 1,4-benzene dicarboxylic acid, 1,3,5-benzene tricarboxylic acid, 1,2,4,5-benzene tetracarboxylic acid were used as organic precursors combined with TMA as inorganic precursor to grow amorphous hybrid films with low surface roughness.[41]

When the 1,4-benzene dicarboxylic acid or so-called terephthalic acid (TPA) was combined with copper 2,2,6,6-tetramethyl-3,5-heptanedione as metal source, highly crystalline copper(II) terephthalate MOF thin films were obtained.[45]Additionally, crystalline Li-organic thin films were deposited with lithium hexamethyldisilazide (LiHMDS) and hydroquinone (HQ) as precursors. It was found that the deposited 
films undergo a reversible structural transformation upon exposure to ambient humid air. DFT calculations suggest that this may be related to an unsaturated Li site in the crystal structure.[46]

Amorphous hybrid films were also deposited using the promising transition metal precursor for ALD/MLD, copper bisdimethylaminopropoxide $\left(\mathrm{Cu}(\mathrm{dmap})_{2}\right)$ combined with a variety of organic precursors i.e. HQ, TPA, 4,4'-oxydianiline (ODA), p-phenylenediamine (PD) and 1,4-benzenedithiol (BDT).[47]

In a previous study, DFT methods were employed to investigate the reactivity between the most common ALD precursor TMA and the functional groups $\mathrm{OH}, \mathrm{NH}_{2}$ and $\mathrm{NO}_{2}$ in the respective substituted phenyls using gas phase models (that neglect the surface and substrate). From theoretical data it was evident that reactions of TMA with $\mathrm{NH}_{2}$ or $\mathrm{NO}_{2}$ functional groups are lower than with $\mathrm{OH}$.[36] However, the detailed chemistry of hybrid films grown using aromatic molecules has not been studied with explicit surface models.

The proper design of organic precursors is very important in ALD/MLD when it comes to film properties. The organic precursor consists of a backbone that can be allyl or aryl, which remains in the hybrid film and the terminal/functional groups which are mostly responsible for the reactivity towards the metal precursor. In alucone films the terminal groups are hydroxyl $(\mathrm{OH})$ groups, [38] but there are many other functional groups already successfully employed: thiol $(\mathrm{SH}),[47]$ amino $\left(\mathrm{NH}_{2}\right),[48]$ carboxylic acid $(\mathrm{COOH}),[49]$ and sulfonic acid $\left(\mathrm{SO}_{3} \mathrm{H}\right)$. [50] The choice of the terminal group naturally defines which atom of the organic precursor $(\mathrm{O}, \mathrm{N}$ or $\mathrm{S})$ is bonded to the metal atom of the inorganic precursor in the resultant metal-organic film and this may be important for the film properties.

In this contribution, we aim to understand the atomic level details of the deposition of $\mathrm{OH}$ and $\mathrm{NH}_{2}$ terminated aromatic molecules in hybrid structures with $\mathrm{Al}_{2} \mathrm{O}_{3}$ and present a first principles investigation of the molecular mechanism of the growth of these films grown in an MLD process. We investigate in detail the chemistry of the MLD process between the post-TMA pulse methyl-terminated $\mathrm{Al}_{2} \mathrm{O}_{3}$ surface and the homo- or hetero-bifunctional aromatic compounds with hydroxy and/or amino groups as reactive groups: hydroquinone (HQ), p-phenylenediamine (PD) and 4-aminophenol (AP). We analyse the reactions between the methyl-terminated $\mathrm{Al}_{2} \mathrm{O}_{3}$ with substituted phenyls to examine the influence of phenyl functionalization on the interaction between the $\mathrm{O}$ and $\mathrm{N}$ site of the aromatic molecules and the Al site of TMA. We also examine the reactivity of TMA with new possible MLD organic precursors as hydroquinone bis(2-hydroxyethyl)ether and 1,1'-biphenyl-4,4'-diamine. DFT calculations suggest a higher reactivity of the $\mathrm{OH}$ group with TMA in comparison to the $\mathrm{NH}_{2}$ group and this enables the double reactions for molecules with $\mathrm{OH}$ terminated groups. Therefore, aromatic molecules with $\mathrm{NH}_{2}$ terminal active groups could be a good option to promote film growth. We also found that the functionalization of the aromatic molecules can have an impact on the deposition chemistry of Al-organic films and change the preference of the aromatic from flat-lying to upright.

\section{Computational methods}

All reported surface calculations are carried out with DFT using the Vienna Ab initio Simulation Package (VASP) version 5.4. [51] The core electrons are treated by projector augmented wave (PAW) potentials [52] and the valence electronic configurations of the atoms used in these calculations are $\mathrm{Al}$ : $3 \mathrm{~s}^{2} 3 \mathrm{p}^{1}, \mathrm{O}: 2 \mathrm{~s}^{2} 2 \mathrm{p}^{4}, \mathrm{~N}: 2 \mathrm{~s}^{2} 2 \mathrm{p}^{3}, \mathrm{C}: 2 \mathrm{~s}^{2} 2 \mathrm{p}^{2}, \mathrm{Cl}: 3 \mathrm{~s}^{2} 3 \mathrm{p}^{5}$ and $\mathrm{H}: 1 \mathrm{~s}^{1}$. The exchange-correlation functional is approximated by the Perdew-Burke-Ernzerhof (PBE) approximation. [53] The reaction between aromatic molecules at $\mathrm{Al}\left(\mathrm{CH}_{3}\right)$-terminated $\mathrm{Al}_{2} \mathrm{O}_{3}$ was used as a model system and the $\alpha-\mathrm{Al} 2 \mathrm{O} 3$ slab used for these calculations was taken from previous work. [54] The geometry was optimized by relaxing the ionic positions, using an energy cut-off of $400 \mathrm{eV}$ as well as a Monkhorst-Pack k-point sampling grid of $(3 \times 3 \times 1)$. The convergence criterion for the forces is $E_{\text {diffG }}=2 \times 10^{-2} \mathrm{eV} \AA^{-1}$ and the energy convergence criteria is $\mathrm{E}_{\text {diff }}=1 \times 10^{-4} \mathrm{eV}$. The computed equilibrium lattice parameters are $\mathrm{a}=\mathrm{b}=$ $9.614 \AA, c=25.25 \AA$ and $\alpha=\beta=90^{\circ}, \gamma=120^{\circ}$. 
Interaction energies between aromatic molecules and the $\mathrm{Al}\left(\mathrm{CH}_{3}\right)$-terminated $\mathrm{Al}_{2} \mathrm{O}_{3}$ are calculated using:

$E_{\text {int }}=\sum E_{p}-\sum E_{r}$

Where $E_{p}$ and $E_{r}$ are the energies of products and of reactants, respectively.

For the example of hydroquinone (HQ) interacting with $\mathrm{Al}\left(\mathrm{CH}_{3}\right) \mathrm{Al}^{-} \mathrm{Al}_{2} \mathrm{O}_{3}$ :

$\left.\mathrm{E}_{\text {int }}=\left[\mathrm{E}\left(\mathrm{HQ}-\mathrm{Al}-\mathrm{Al}_{2} \mathrm{O}_{3}\right)+\left(\mathrm{CH}_{4}\right)\right]-\left[\mathrm{E}\left(\mathrm{CH}_{3}\right)-\mathrm{Al}_{-}-\mathrm{Al}_{2} \mathrm{O}_{3}\right)+(\mathrm{HQ})\right]$

A negative $\mathrm{E}_{\text {int }}$ signifies an exothermic interaction and therefore the interaction is favourable.

\section{Results}

\subsection{Reactions between aromatic molecules and $\mathrm{TMA}$ on $\mathrm{Al}_{2} \mathrm{O}_{3}$ surface}

The hydroxylated $\mathrm{Al}_{2} \mathrm{O}_{3}$ surface terminated with one methyl group ( $\left.\mathrm{MMA}-\mathrm{Al}_{2} \mathrm{O}_{3}\right)$ that results from the adsorption of trimethylaluminium (TMA) on the $\mathrm{Al}_{2} \mathrm{O}_{3}$ surface was taken from our previous work with alucones. [37] We performed fundamental investigations on the interactions between the post-TMA pulse methyl-terminated $\mathrm{Al}_{2} \mathrm{O}_{3}$ surface and a selection of aromatic molecules with very different chemical character and these are hydroquinone (HQ), p-phenylenediamine (PD) and 4-aminophenol (AP), Figure 1.

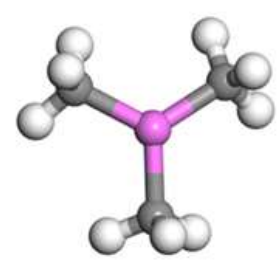

trimethylaluminum (TMA)

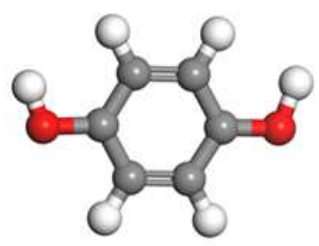

hydroquinone ( $\mathrm{HQ})$

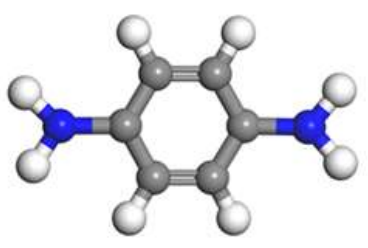

p-phenylenediamine

(PD)

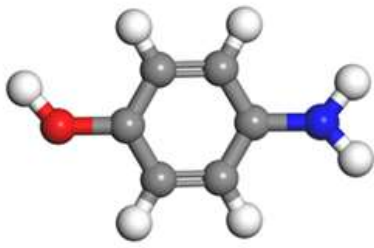

4-aminophenol

(AP)

Fig. 1 Structures of trimethylaluminum (TMA), hydroquinone (HQ), p-phenylenediamine (PD), and 4aminophenol (AP) after optimization by DFT. Purple-Aluminium, Red-Oxygen, Grey-Carbon, Blue-Nitrogen, White-Hydrogen. Figure coding is the same for all figures.

This set of aromatic molecules allows us to examine the reactivity of hydroxyl $(\mathrm{OH})$ and amino $\left(\mathrm{NH}_{2}\right)$ groups towards TMA as well as the preferred orientation of the organic species. The selected aromatic molecules contain $\mathrm{OH}$ and $\mathrm{NH}_{2}$ groups separated by an aromatic ring where the $\mathrm{OH}$ and $\mathrm{NH}_{2}$ groups serve as reactive linkers for condensation reactions with metal sites, leading to hybrid films.

The modeling was done considering the potential proton transfer, elimination of methane molecules $\left(\mathrm{CH}_{4}\right)$ and the formation of new Al-O and Al-N bonds. The $\mathrm{OH}$ and $\mathrm{NH}_{2}$ groups have lone electron pairs with Lewis basie character and can bind with the methyl ligands $\left(\mathrm{CH}_{3}\right)$ of TMA which have a strong Lewis acid character and eliminate as $\mathrm{CH}_{4}$. The initial reaction between TMA with HQ and PD are likely to be as follows: 


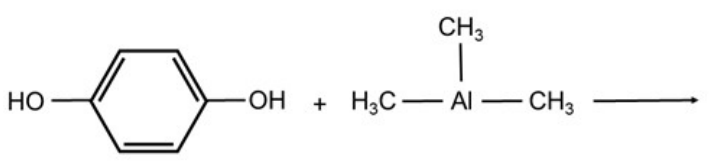

$\longrightarrow-\mathrm{Ol}-\mathrm{CH}_{3}+\mathrm{CH}_{4}$
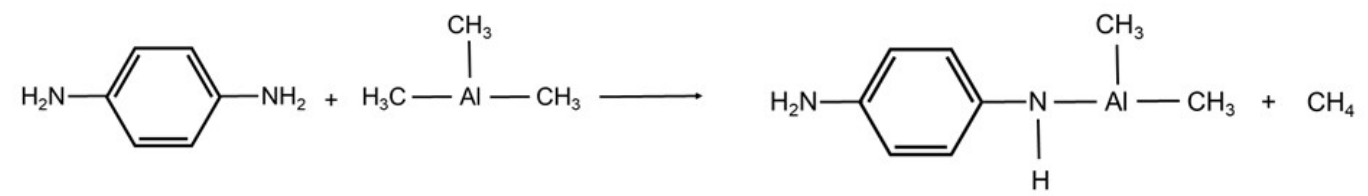

Scheme 1 Schematic representation of the proposed reaction mechanism of TMA with HQ (R1) and PD (R2) in the gas phase. Reproduced with permission from ref. [36]

The AP molecule is a heterobifuntional aromatic molecule that contains both active groups, $\mathrm{OH}$ and $\mathrm{NH}_{2}$. Therefore, AP can react with TMA according to R1 or R2. [36] The optimized atomic structures of the MLD products with HQ, PD and AP are shown in Figure 2. In the first calculations the aromatic precursors were modelled in an upright configuration. When these aromatic molecules react with TMA adsorbed on the $\mathrm{Al}_{2} \mathrm{O}_{3}$ surface, a proton from a terminal active group $\left(\mathrm{OH}\right.$ or $\left.\mathrm{NH}_{2}\right)$ transfers to the $\mathrm{CH}_{3}$ ligand of TMA to form a new $\mathrm{CH}_{4}$ molecule that is released as a by-product.

For HQ the remaining $\mathrm{O}$ binds to Al of TMA with a Al-O distance $1.73 \AA$, and the calculated energy change for this reaction is $-1.38 \mathrm{eV}$. For PD the remaining $\mathrm{N}$ binds to Al of TMA with a Al-N distance of $1.83 \AA$, and the calculated energy change for this reaction is $-1.12 \mathrm{eV}$. Calculated energetics show that HQ and PD molecules bind favourably with TMA on $\mathrm{Al}_{2} \mathrm{O}_{3}$ via formation of new Al-O and Al-N bonds and $\mathrm{CH}_{4}$ elimination. However, reaction energetics suggest a higher reactivity of the $\mathrm{OH}$ group with TMA in comparison to the $\mathrm{NH}_{2}$ group.

Containing both active groups, $\mathrm{OH}$ and $\mathrm{NH}_{2}$, AP can bind to Al of TMA through $\mathrm{O}$ with a calculated Al-O distance $1.71 \AA$ and through $\mathrm{N}$ with a calculated Al-N distance $1.83 \AA$. A higher reactivity was calculated again for the reaction with the $\mathrm{OH}$ group with an energy change $-1.25 \mathrm{eV}$ for the Al-O bonding in comparison to the $\mathrm{NH}_{2}$ group with an energy change of $-0.86 \mathrm{eV}$ for the Al-N bonding.

In addition to the Al-O and Al-N bonds formed with the aromatic molecules, the $\mathrm{Al}$ atom is bonded to three surface oxygen sites with distances $2.0 \AA, 1.78 \AA$ and $1.75 \AA$ in the reaction with HQ, $1.94 \AA$, $1.92 \AA$ and $1.73 \AA$ in the reaction with $\mathrm{PD}$ and $2.0 \AA, 1.78 \AA$ and $1.75 \AA$ in the reaction with AP. After the interactions with the aromatic molecules the coordination number of the Al atom of TMA and the

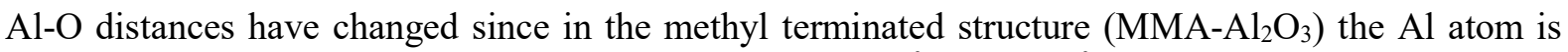
bonded with two surface oxygens with Al-O distances $1.78 \AA$ and $1.76 \AA$.

The results of this set of calculations are consistent with the findings of the gas phase model that was used to examine the interactions between TMA and the functional groups $\mathrm{OH}, \mathrm{NH}_{2}$, and $\mathrm{NO}_{2}$ in the respective substituted phenyl molecules with $\mathrm{DFT}^{36}$. While that model accounts for the Al-O/Al-N bond formation, it lacks the alumina surface which is an important part of the growth chemistry. However, that study does show that the reactions between TMA and the functional groups are exothermic. It was also found that the reaction energy for TMA with $\mathrm{NH}_{2}$ or $\mathrm{NO}_{2}$ functional groups is considerably less favourable than with $\mathrm{OH}$. 


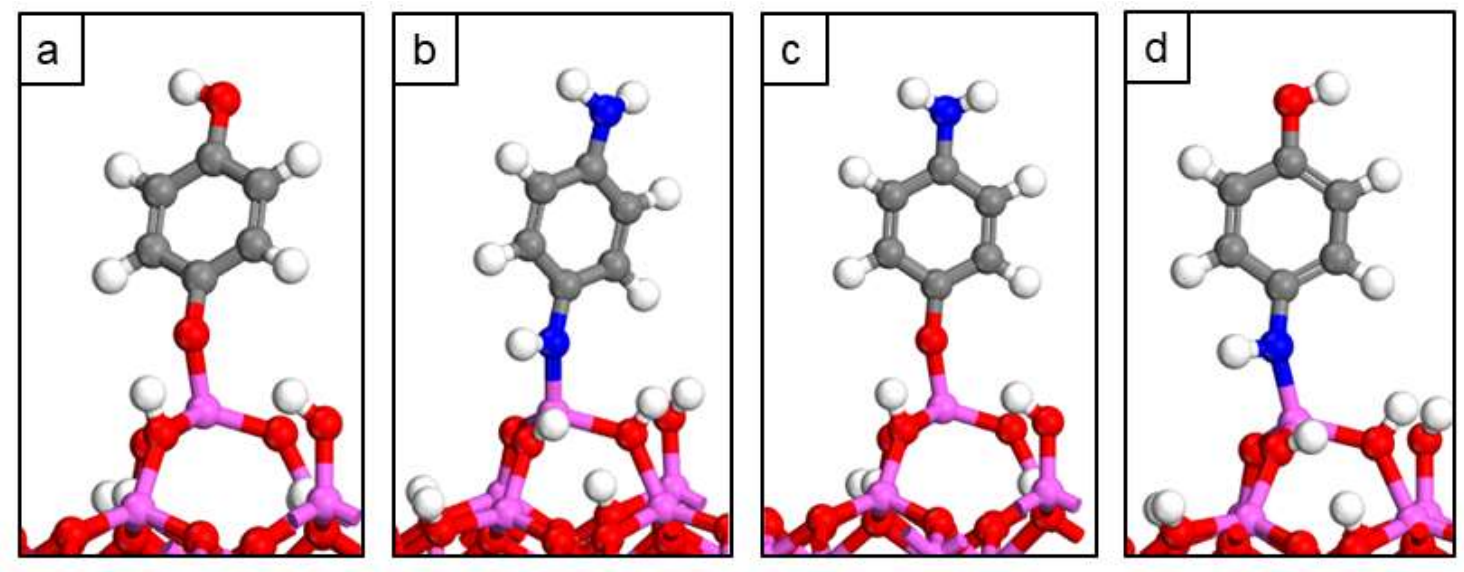

Fig. 2 Atomic structures of MLD reaction products of the interaction of the MMA- $\mathrm{Al}_{2} \mathrm{O}_{3}$ surface with (a) HQ (b) PD (c) AP, Al-O bonding and (d) AP, Al-N bonding.

Table 1 Computed interaction energy upon formation of $\mathrm{Al}-\mathrm{O}$ and $\mathrm{Al}-\mathrm{N}$ bonds between $\mathrm{MMA}-\mathrm{Al}_{2} \mathrm{O}_{3}$ and the organic molecules of interest.

\begin{tabular}{|l|c|}
\hline Structure & Interaction energy $(\mathrm{eV})$ \\
\hline MMA- $\mathrm{Al}_{2} \mathrm{O}_{3}-\mathrm{HQ}$ & -1.38 \\
\hline MMA- $\mathrm{Al}_{2} \mathrm{O}_{3}-\mathrm{PD}$ & $-1-12$ \\
\hline MMA- $\mathrm{Al}_{2} \mathrm{O}_{3}-\mathrm{AP}(\mathrm{Al}-\mathrm{O})$ & -1.25 \\
\hline MMA- $\mathrm{Al}_{2} \mathrm{O}_{3}-\mathrm{AP}(\mathrm{Al}-\mathrm{N})$ & -0.86 \\
\hline
\end{tabular}

\subsection{Comparison of upright and flat-lying reactions of HQ, PD and AP}

To investigate the double reaction phenomenon for the aromatic molecules in more detail, we examine interactions of the $\mathrm{Al}_{2} \mathrm{O}_{3}$ surface terminated with two surface bound $\mathrm{Al}\left(\mathrm{CH}_{3}\right)$ species $\left(2 \mathrm{MMA}-\mathrm{Al}_{2} \mathrm{O}_{3}\right)$, used in our previous work [37], with HQ, PD and AP molecules in the upright and flat lying configuration. Minimising double reactions of the organic precursor is considered an important advantage of using stiff aromatic molecules as organic precursors. While in the upright configuration the aromatic molecules bind to $\mathrm{Al}$ sites through one active group and one $\mathrm{CH}_{4}$ molecule is released, in the flat configuration, the aromatic molecules bind through both active groups with two neighbouring $\mathrm{Al}$ sites and two $\mathrm{CH}_{4}$ molecules are released.

MLD reaction products of TMA adsorbed at $\mathrm{Al}_{2} \mathrm{O}_{3}$ surface with the upright and flat lying HQ, PD and AP molecules are shown in Figure 3. The computed change in energy when the aromatic molecules bind with one $\mathrm{Al}$ site in the upright configuration and with two $\mathrm{Al}$ sites in the flat lying configuration are shown in Table 2. The energy change given for the double reaction is with reference to the upright structure and allows us to assess if the double reaction is thermodynamically favourable.

Aromatic molecules interact favourably with TMA in an upright configuration with an energy gain ranging from $-0.49 \mathrm{eV}$ for $\mathrm{PD}$ to $-1.69 \mathrm{eV}$ for $\mathrm{HQ}$. Once again the calculated energies show that the reaction is more exothermic for the formation of the Al-O bond in comparison to the formation of the Al-N bond.

Calculated energies for the flat configuration of organic molecules shown in Table 2 represent the overall energy when the upright molecule becomes flat and a second $\mathrm{CH}_{4}$ molecule is released. This energy change is $-0.11 \mathrm{eV}$ for the double reaction of $\mathrm{HQ}$ on the $2 \mathrm{MMA}-\mathrm{Al}_{2} \mathrm{O}_{3}$ surface and shows that the molecule can also lie flat and react twice with the surface. 
In contrast to HQ, calculated energies for the double reactions of PD and AP with TMA are endothermic thereby not favourable. PD and AP molecules do not prefer to lie flat and react twice with Al sites and this might be due to the presence of $\mathrm{NH}_{2}$ active groups for which a lower reactivity with TMA was calculated.

When we compare the $\mathrm{Al}-\mathrm{O}$ and $\mathrm{Al}-\mathrm{N}$ distances between the upright models and flat lying models we see that the $\mathrm{Al}-\mathrm{O}$ and $\mathrm{Al}-\mathrm{N}$ distances to the aromatic molecule undergo small changes. For the HQ molecule bonded on the MMA- $\mathrm{Al}_{2} \mathrm{O}_{3}$ surface the $\mathrm{Al}-\mathrm{O}$ bond is lengthen from $1.71 \AA$ to $1.82 \AA$ while for AP the Al-O distance is lengthen from $1.69 \AA$ to $1.83 \AA$. For the PD molecule the Al-N distance is lengthen from $1.80 \AA$ to $1.91 \AA$.

Based on the calculated energetics for the double reactions of aromatic molecules, HQ can react with both $\mathrm{OH}$ groups with TMA on the $\mathrm{Al}_{2} \mathrm{O}_{3}$ surface and form the double reactions. This phenomenon leaves the surface covered with no OH sites to react with TMA in the next pulse. However, the small exothermic energy change suggests that the two binding modes of HQ will be competitive. For PD and AP, because of the presence of the $\mathrm{NH}_{2}$ group, the unwanted double reactions on the surface are efficiently reduced and the molecules can self-assemble in a vertical orientation with a free - $\mathrm{OH}$ or $\mathrm{NH}_{2}$ group for the next cycle. Hence, the surface remains covered with $\mathrm{NH}_{2}$ groups that react with TMA in the next pulse. This will lead to thicker PD and AP based Al-organic films compared to HQ based $\mathrm{Al}$-organic films. This is consistent with work on $\mathrm{TiO}_{2}$ based MLD films that are grown using HQ, PD, AP and ODA molecules as organic precursors. [55] We expect PD and AP based Al-organic films to have the same thickness as PD and AP molecules have similar backbone lengths as well (5.5 $\AA$ and 5.6 $\AA)$.

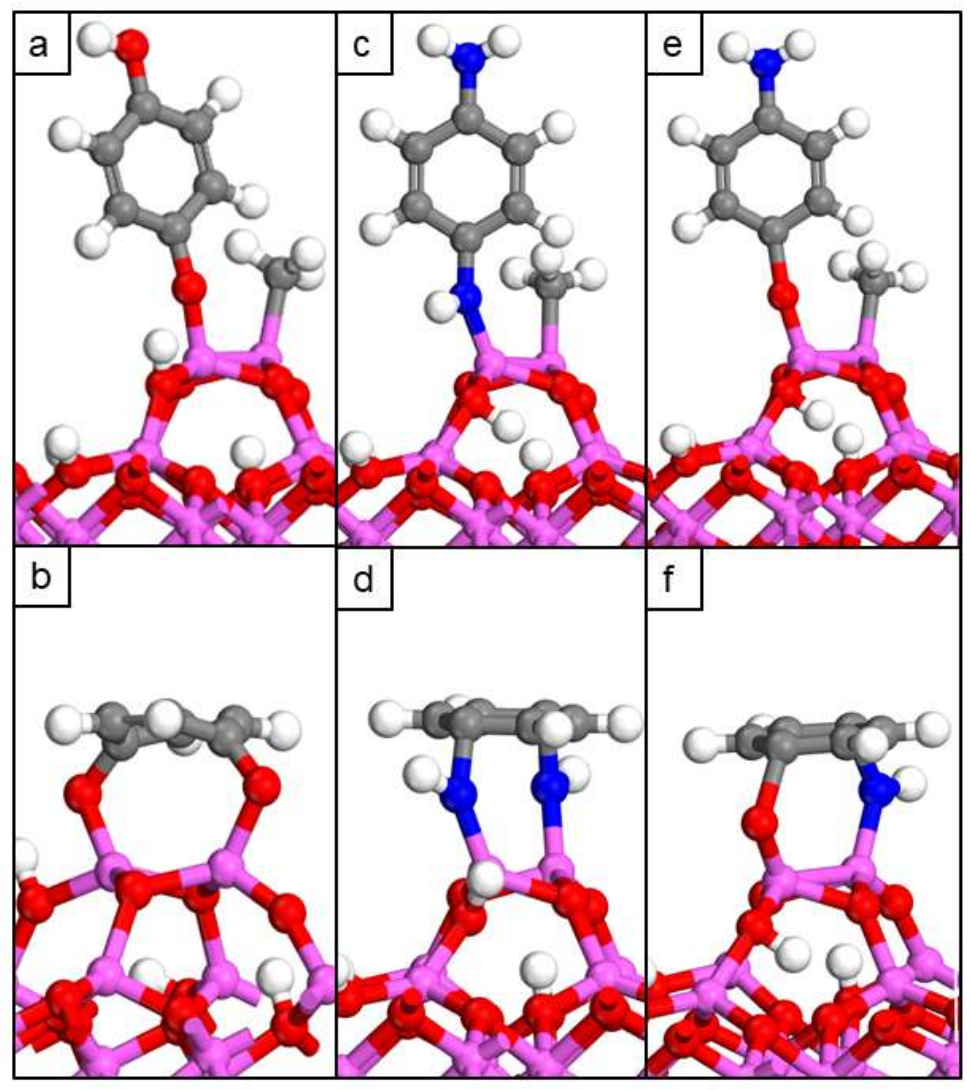

Fig. 3 MLD reaction products of the interaction of the $M M A-\mathrm{Al}_{2} \mathrm{O}_{3}$ surface with (a) upright $\mathrm{HQ}$, (b) flat $\mathrm{HQ}$, (c) upright PD (d) flat PD, (e) upright AP and (f) flat AP. 
Table 2 Computed interaction energy, upon formation of $\mathrm{Al}-\mathrm{O}$ and $\mathrm{Al}-\mathrm{N}$ bonds between $\mathrm{MMA}-\mathrm{Al}_{2} \mathrm{O}_{3}$ in the upright configuration of HQ, PD and AP. The energy change between the flat (double reaction) and upright configurations is also presented.

\begin{tabular}{|l|c|}
\hline Structure & Interaction energy $(\mathrm{eV})$ \\
\hline $2 \mathrm{MMA}-\mathrm{Al}_{2} \mathrm{O}_{3}-\mathrm{HQ}-$ upright & -1.69 \\
\hline $2 \mathrm{MMA}-\mathrm{Al}_{2} \mathrm{O}_{3}-\mathrm{PD}-$ upright & -0.49 \\
\hline 2MMA- $\mathrm{Al}_{2} \mathrm{O}_{3}-\mathrm{AP}(\mathrm{Al}-\mathrm{O})$ - upright & -1.19 \\
\hline 2MMA- $\mathrm{Al}_{2} \mathrm{O}_{3}-\mathrm{HQ}$ - flat & -0.11 \\
\hline $2 \mathrm{MMA}-\mathrm{Al}_{2} \mathrm{O}_{3}-\mathrm{PD}$ - flat & 1.01 \\
\hline 2MMA- $\mathrm{Al}_{2} \mathrm{O}_{3}-\mathrm{AP}-$ flat & 0.31 \\
\hline
\end{tabular}

We also computed interaction energies with van der Waals forces (VdW), Table $\mathbf{3}$, and we find that there is generally a small impact due to including VdW interaction. However, for HQ the inclusion of the VdW interactions makes the double reactions for the HQ molecule less favourable.

Table 3 Computed interaction energy with Van der Waals forces (VdW) on, upon formation of Al-O and Al-N bonds between $\mathrm{MMA}-\mathrm{Al}_{2} \mathrm{O}_{3}$ in the upright configuration of $\mathrm{HQ}, \mathrm{PD}$ and $\mathrm{AP}$. The energy change between the flat (double reaction) and upright configurations is also presented.

\begin{tabular}{|l|c|}
\hline Structure & Interaction energy $(\mathrm{eV})$ \\
\hline 2MMA- $\mathrm{Al}_{2} \mathrm{O}_{3}-\mathrm{HQ}-$ upright & -1.42 \\
\hline 2MMA- $\mathrm{Al}_{2} \mathrm{O}_{3}-\mathrm{PD}-$ upright & -0.38 \\
\hline 2MMA- $\mathrm{Al}_{2} \mathrm{O}_{3}-\mathrm{AP}(\mathrm{Al}-\mathrm{O})$ - upright & -1.13 \\
\hline 2MMA- $\mathrm{Al}_{2} \mathrm{O}_{3}-\mathrm{HQ}-$ flat & 0.25 \\
\hline 2MMA- $\mathrm{Al}_{2} \mathrm{O}_{3}-\mathrm{PD}$ - flat & 1.17 \\
\hline 2MMA- $\mathrm{Al}_{2} \mathrm{O}_{3}-\mathrm{AP}-$ flat & 0.35 \\
\hline
\end{tabular}

\subsection{Reaction of HQ, PD and AP with TMA}

Next we examine the reactivity of HQ, PD and AP molecules with a TMA precursor molecule, which takes place in the second cycle of the MLD process. After loss of $\mathrm{CH}_{4}$, these structures can be described as $\mathrm{Al}_{2} \mathrm{O}_{3}$-MMA-HQ-DMA, $\mathrm{Al}_{2} \mathrm{O}_{3}$-MMA-PD-DMA and $\mathrm{Al}_{2} \mathrm{O}_{3}$-MMA-AP-DMA, where DMA stands for $\mathrm{Al}\left(\mathrm{CH}_{3}\right)_{2}$. During the reaction with TMA, the remaining $\mathrm{OH}$ and $\mathrm{NH}_{2}$ groups of aromatic molecules react with TMA and form new Al-O or Al-N bonds and one $\mathrm{CH}_{4}$ molecule is released. Optimised structures for the products of the MLD reactions in the second cycle are shown in Figure 4. For HQ the energy change upon forming a new $\mathrm{Al}-\mathrm{O}$ bond with distance $1.70 \AA$, together with release of $\mathrm{CH}_{4}$, is $-1.48 \mathrm{eV}$. Since we found that HQ can also lie flat and react with TMA via both $\mathrm{OH}$ groups, we also examine the reactivity of the flat lying HQ towards TMA. We consider the reaction between a terminal $\mathrm{O}$ of HQ with TMA as shown in Figure $\mathbf{4 b}$. The energy change in forming an Al-O bond between HQ and TMA is $-0.68 \mathrm{eV}$. Calculated energetics indicate that HQ in both configurations is reactive towards TMA. 


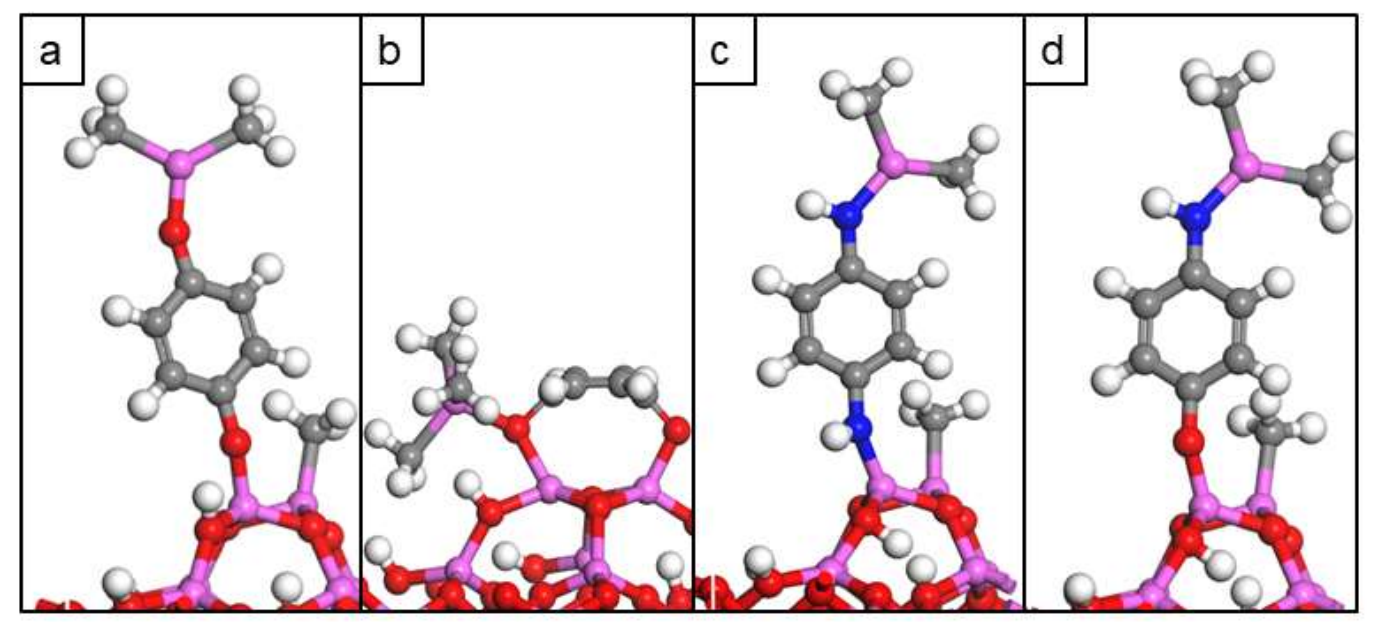

Fig. 4 Atomic structure of (a) up-right HQ with adsorption of TMA at the exposed O site on HQ (b) flat lying HQ with adsorption of TMA at the exposed $\mathrm{O}$ site on HQ, (c) up-right PD with adsorption of TMA at the exposed N site on PD and (d) up-right AP with adsorption of TMA at the exposed N site on AP.

For PD and AP, the energy change upon forming new Al-N bonds with distance $1.80 \AA$, together with release of $\mathrm{CH}_{4}$ are $-0.71 \mathrm{eV}$ and $-0.92 \mathrm{eV}$ respectively. When we compare the reaction energetics between the three aromatic molecules in the upright configuration with TMA, a lower reactivity of the $\mathrm{NH}_{2}$ group with TMA in comparison to the $\mathrm{OH}$ group was again noted. However, the reactions between the three aromatic molecules and TMA in the second cycle of the MLD process are exothermic and this indicates that the exposed $\mathrm{OH}$ and $\mathrm{NH}_{2}$ groups are reactive to TMA and further growth will proceed for HQ, PD and AP based Al-organic films.

\subsection{The influence of phenyl functionalization}

The molecules 2-methoxyhydroquinone $\left(\mathrm{HQ}-\mathrm{OCH}_{3}\right)$, 2-methylhydroquinone $\left(\mathrm{HQ}-\mathrm{CH}_{3}\right)$, 2chlorhydroquinone (HQ-Cl) and 2-nitrohyrdoquinone $\left(\mathrm{HQ}-\mathrm{NO}_{2}\right)$ were chosen to examine the role of phenyl functionalization on the interaction between the $\mathrm{O}$ site of the HQ molecule and the Al site of TMA. This set of calculations allows us to analyse the influence of the activating groups $-\mathrm{OCH}_{3},-\mathrm{CH}_{3}$ and deactivating groups $-\mathrm{Cl}$ and $-\mathrm{NO}_{2}$ on the Al-O bond. The substitution of the $\mathrm{H}$ atom on the HQ molecule was done in the meta position and the reaction mechanism between the functionalized molecules and TMA is according to R1. Optimised structures of the functionalized HQ molecule reacting with TMA on the $\mathrm{Al}_{2} \mathrm{O}_{3}$ surface are shown on Figure 5.

Although activating and deactivating groups impact the stability and the reactivity of the aromatic ring in different ways, there is no big difference on the calculated energies for four reactions of TMA with the aromatic molecules. Calculated energies are $-1.21 \mathrm{eV}$ for the reaction with $\mathrm{HQ}-\mathrm{OCH}_{3},-1.25 \mathrm{eV}$ for the reaction with $\mathrm{HQ}-\mathrm{CH}_{3},-1.30 \mathrm{eV}$ for the reaction with $\mathrm{HQ}-\mathrm{Cl}$ and $-1.25 \mathrm{eV}$ for the reaction with HQ$\mathrm{NO}_{2}$. Calculated energies for the reaction between the functionalized HQ molecule with TMA on the $\mathrm{Al}_{2} \mathrm{O}_{3}$ surface do not differ much also from the calculated energy for the reaction between the unmodified $\mathrm{HQ}$ with TMA on $\mathrm{Al}_{2} \mathrm{O}_{3}$ surface $(-1.38 \mathrm{eV})$.

However, small changes were observed on the Al-O bond when the aromatic molecule is modified with activating and deactivating groups. The Al-O distance for the unmodified HQ model is $1.73 \AA$ and it decreases to $1.71 \AA$ for $\mathrm{HQ}-\mathrm{OCH}_{3}, \mathrm{HQ}-\mathrm{CH}_{3}$, and $\mathrm{HQ}-\mathrm{Cl}$, while there is an increase to $1.74 \AA$ for HQ$\mathrm{NO}_{2}$. 
The calculations show that the functionalisation of the aromatic ring can be done with the purpose to improve film properties and importantly this will not weaken the interaction between aromatic molecules and the TMA precursor nor the stability of the system.

Given the possibility of the double reaction for the HQ molecule, a flat configuration of the $\mathrm{HQ}-\mathrm{OCH}_{3}$, $\mathrm{HQ}-\mathrm{CH}_{3}, \mathrm{HQ}-\mathrm{Cl}$ and $\mathrm{HQ}-\mathrm{NO}_{2}$ on the $2 \mathrm{MMA}-\mathrm{Al}_{2} \mathrm{O}_{3}$ was examined. The reaction energies are now endothermic with a calculated energy of $0.20 \mathrm{eV}$ for $\mathrm{HQ}-\mathrm{OCH}_{3}, 0.01 \mathrm{eV}$ for $\mathrm{HQ}-\mathrm{CH}_{3}, 0.11 \mathrm{eV}$ for $\mathrm{HQ}-$ $\mathrm{Cl}$ and $0.29 \mathrm{eV}$ for $\mathrm{HQ}-\mathrm{NO}_{2}$ on the $2 \mathrm{MMA}-\mathrm{Al}_{2} \mathrm{O}_{3}$. Calculated energies indicate that phenyl functionalisation can have an impact on the configuration of the aromatic molecule by hindering the molecule to lie flat and react twice with the surface. This promotes an upright binding mode and thicker film growth compared to an unfunctionalised phenyl ring.

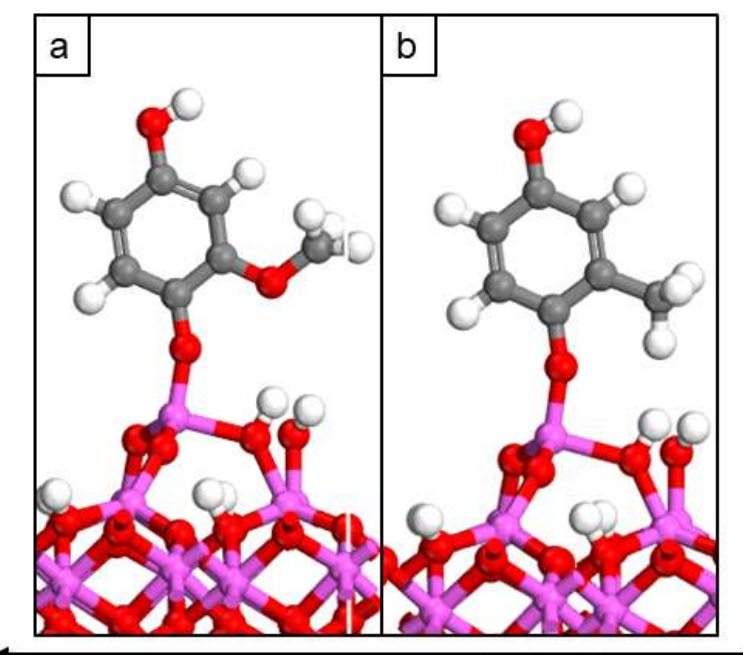

Strongly activating

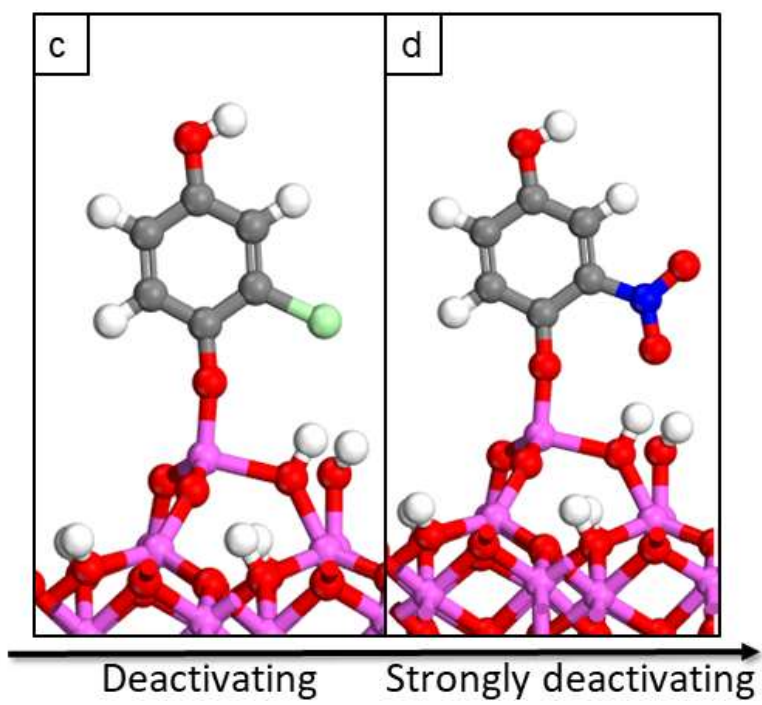

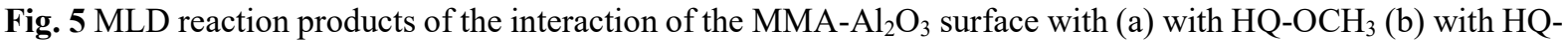
$\mathrm{CH}_{3}$, (c) with $\mathrm{HQ}-\mathrm{Cl}$ and (d) with $\mathrm{HQ}-\mathrm{NO}_{2}$.

We also evaluate the role of phenyl functionalization on the interaction between the $\mathrm{N}$ site of the PD molecule and the Al site of TMA. Again the substitution of the $\mathrm{H}$ atom on the PD molecule was done in the meta position while the reaction mechanism between the functionalized PD molecule and TMA is according to R2. Optimised structures of the functionalized PD molecule reacting with TMA on the $\mathrm{Al}_{2} \mathrm{O}_{3}$ surface are shown on Figure 6. Calculated energies are $-1.25 \mathrm{eV}$ for the reaction with $\mathrm{PD}-\mathrm{OCH}_{3}$, $-1.20 \mathrm{eV}$ for the reaction with $\mathrm{PD}-\mathrm{CH}_{3},-1.42 \mathrm{eV}$ for the reaction with $\mathrm{PD}-\mathrm{Cl}$ and $-1.49 \mathrm{eV}$ for the reaction with $\mathrm{PD}-\mathrm{NO}_{2}$. The calculated energies between the functionalized PD molecules and TMA on $\mathrm{Al}_{2} \mathrm{O}_{3}$ surface are more negative compared to the energy for the reaction between the unmodified PD with TMA on $\mathrm{Al}_{2} \mathrm{O}_{3}$ surface $(-1.12 \mathrm{eV})$. This shows that for $\mathrm{PD}$, the functionalization of the molecule can also impact the chemistry of the $\mathrm{NH}_{2}$ group with TMA by increasing the interactions between the precursors. Small changes are also observed on the Al-N distance which increased from $1.83 \AA$ for the unmodified PD molecule to $1.84 \AA$ for $\mathrm{PD}-\mathrm{OCH}_{3}, \mathrm{PD}-\mathrm{CH}_{3}$, and $\mathrm{PD}-\mathrm{Cl}$, and $1.88 \AA$ for $\mathrm{PD}-\mathrm{NO}_{2}$. 

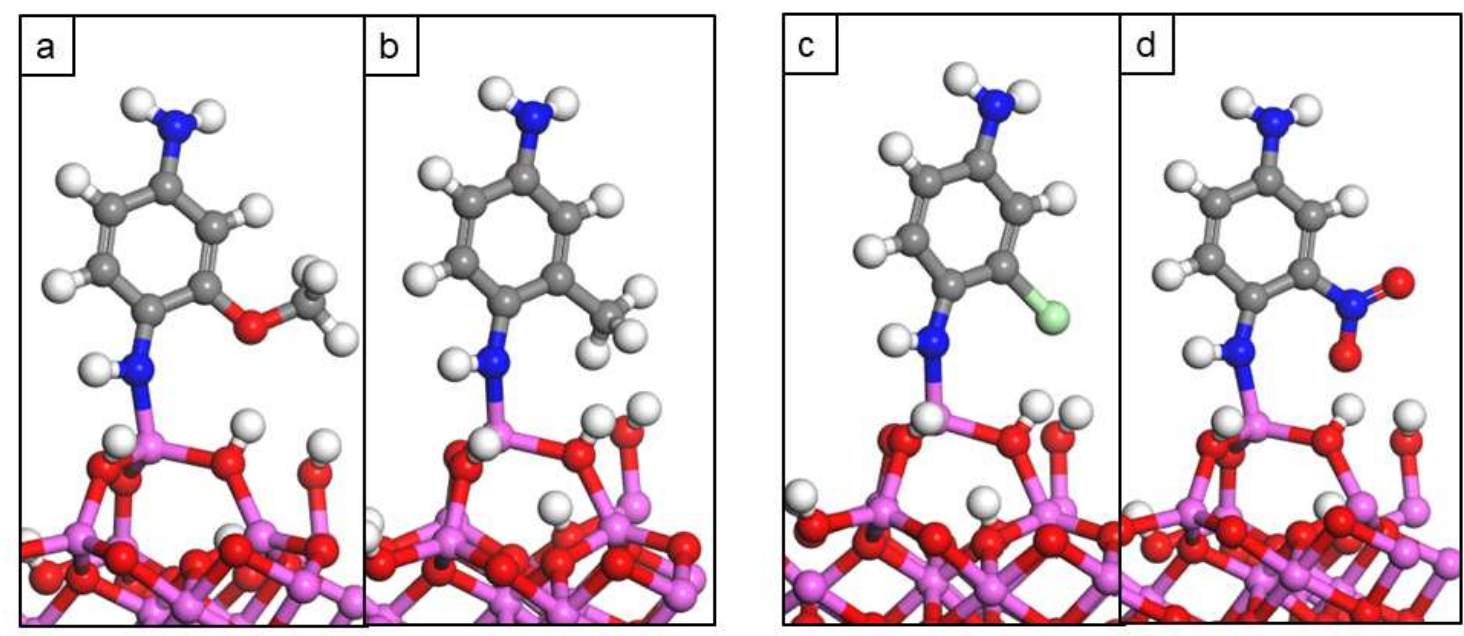

Fig. 6 MLD reaction products of the interaction of the $M M A-\mathrm{Al}_{2} \mathrm{O}_{3}$ surface with (a) with $\mathrm{PD}-\mathrm{OCH}$ (b) with $\mathrm{PD}$ $\mathrm{CH}_{3}$, (c) with PD-Cl and (d) with PD-NO2.

\subsection{Reactions between hydroquinone bis(2-hydroxyethyl)ether and 1,1'-biphenyl-4,4'-diamine with MMA terminated $\mathrm{Al}_{2} \mathrm{O}_{3}$ surface}

In our final study we examine the interactions between TMA on the $\mathrm{Al}_{2} \mathrm{O}_{3}$ and the aromatic molecules hydroquinone bis(2-hydroxyethyl)ether $\left(\mathrm{C}_{6} \mathrm{H}_{4}\left(\mathrm{OCH}_{2} \mathrm{CH}_{2} \mathrm{OH}\right)_{2}\right)$ and 1,1'-biphenyl-4,4'-diamine $\left(\left(\mathrm{C}_{6} \mathrm{H}_{4} \mathrm{NH}_{2}\right)_{2}\right)$. None of the selected molecules has been used so far in MLD although similar molecules to 1,1'-biphenyl-4,4'-diamine such as 4,4'-oxydianiline and 4,4'-biphenyldicarboxylic have already been used in practice.[48,56] The hydroquinone bis(2-hydroxyethyl)ether and 1,1'-biphenyl-4,4'diamine have been specifically selected in this study to examine the influence of the length of the organic precursor on the $\mathrm{Al}-\mathrm{O}$ and $\mathrm{N}-\mathrm{O}$ interactions. Calculations with hydroquinone bis(2hydroxyethyl)ether and 1,1'-biphenyl-4,4'-diamine also allow us to assess the impact of the length of the organic precursor on the preferred configuration of the aromatic molecule.

Optimised structures of the MLD reaction products with hydroquinone bis(2-hydroxyethyl)ether and 1,1'-biphenyl-4,4'-diamine are shown in Figure 7. Organic molecules were modelled in the upright configuration. Hydroquinone bis(2-hydroxyethyl)ether molecule contains two hydroxyethyl chains separated by one aromatic ring where the hydroxyethyl chains participate in the reactions with the TMA. During this reaction a proton from the terminal $\mathrm{OH}$ group of the hydroxyethyl chain transfers to the $\mathrm{CH}_{3}$ ligand to form a new $\mathrm{CH}_{4}$ molecule while the remaining $\mathrm{O}$ binds to $\mathrm{Al}$ of TMA with a distance of $1.74 \AA$. The calculated interaction energy, $-1.15 \mathrm{eV}$, confirms that this reaction is favourable. When we compare interaction energies for the reaction of TMA with HQ and with hydroquinone bis(2hydroxyethyl)ether, we see a drop in energy from $-1.38 \mathrm{eV}$ to $-1.15 \mathrm{eV}$. The drop in energy when the size of the aromatic molecule has increased shows that for longer aromatic molecules it will likely be more difficult to maintain an upright configuration compared to lying flat and participate in the double reaction.

The 1,1'-biphenyl-4,4'-diamine molecule contains two $\mathrm{NH}_{2}$ groups separated by two aromatic rings. In this reaction a proton from the terminal $\mathrm{NH}_{2}$ group transfers to the $\mathrm{CH}_{3}$ ligand to form a new $\mathrm{CH}_{4}$ molecule while the remaining $\mathrm{N}$ binds to $\mathrm{Al}$ of TMA with a Al-N distance $1.84 \AA$. This reaction is favourable with an interaction energy of $-0.32 \mathrm{eV}$. When compared to the interaction energy for the PD bonded to TMA, this energy has decreased from $-1.12 \mathrm{eV}$ to $-0.32 \mathrm{eV}$ and again we propose that this drop in energy when the size of the aromatic molecule has increased is due to the difficulty of longer aromatic molecules to maintain in an upright configuration.

In the reactions with hydroquinone bis(2-hydroxyethyl)ether and 1,1'-biphenyl-4,4'-diamine the Al atom of TMA remains four coordinated. The $\mathrm{Al}$ atom is bonded to $\mathrm{O}$ or $\mathrm{N}$ site of the aromatic molecule 
and also to three oxygen atoms on the surface with distances $2.06 \AA, 1.79 \AA$ and $1.76 \AA$ for hydroquinone bis(2-hydroxyethyl)ether and 2.1 $\AA, 1.77 \AA$ and $1.75 \AA$ for 1,1'-biphenyl-4,4'-diamine.

In conclusion, DFT calculations show that the hydroquinone bis(2-hydroxyethyl)ether molecule has potential to be used as an organic precursor for the deposition of hybrid films with MLD. The thermal properties of hydroquinone bis(2-hydroxyethyl)ether also indicate that most probably the compound would be suitable for MLD and DFT studies provide further motivation to develop an MLD process for the deposition of hybrid films using hydroquinone bis(2-hydroxyethyl)ether as organic precursor.
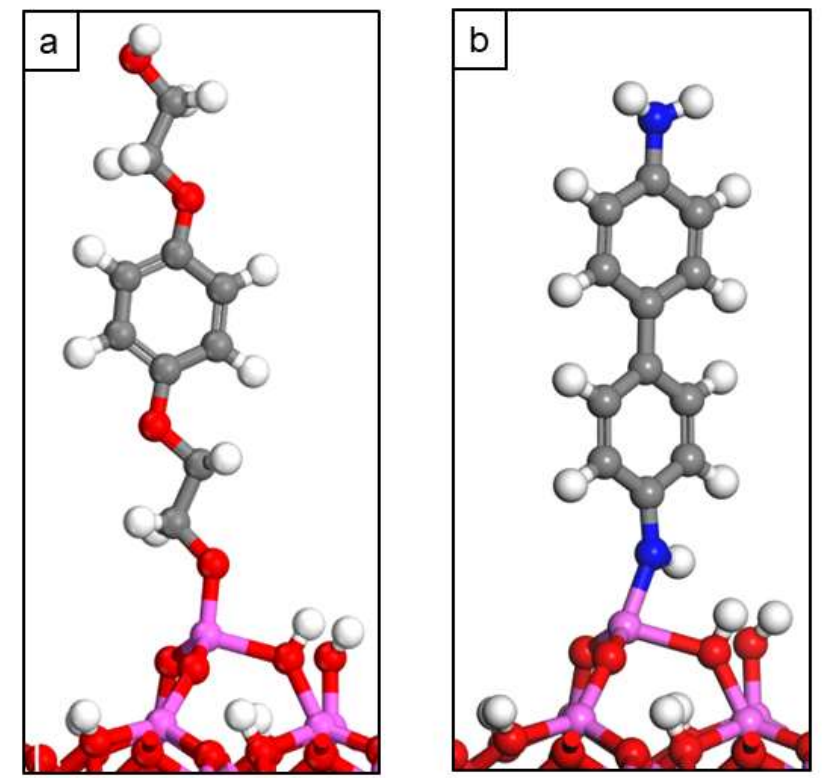

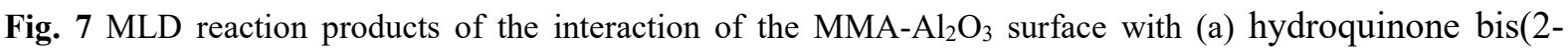
hydroxyethyl)ether and (b) 1,1'-biphenyl-4,4'-diamine.

\section{Conclusions}

In this study, we investigate the molecular mechanism of the growth of Al-organic films deposited by MLD. We investigate in detail the chemistry of the MLD process between the methyl terminated $\mathrm{Al}_{2} \mathrm{O}_{3}$ surface and a selection of aromatic molecules with hydroxyl $(\mathrm{OH})$ and/or amino $\left(\mathrm{NH}_{2}\right)$ functional groups. The selected molecules are: hydroquinone (HQ), p-phenylenediamine (PD) and 4-aminophenol (AP). Reaction energetics show that $\mathrm{HQ}$ and $\mathrm{PD}$ and $\mathrm{AP}$ molecules bind favourably with TMA on $\mathrm{Al}_{2} \mathrm{O}_{3}$ surface via formation of new Al-O and Al-N bonds and $\mathrm{CH}_{4}$ elimination. However, a higher reactivity of the $\mathrm{OH}$ group in comparison to the $\mathrm{NH}_{2}$ group was calculated. Aromatic molecules were also investigated in detail for their double reactions. We found that while the preferred configuration of the $\mathrm{PD}$ and AP molecules is the up right configuration, the energetics would suggest that HQ could also lie flat and react twice with the surface through the two terminal $\mathrm{OH}$ groups, where the terminal oxygen sites bind to Al. However given the energetics with inclusion of vdW interactions and the very small change in energy without $\mathrm{vdW}$ interactions, we propose that the HQ molecules will lie upright. Preventing the double reaction phenomenon maximizes the number of active groups available on the surface to react with TMA in the next pulse. This is consistent with experimental work showing that aromatic molecules are a good option to promote film growth and the deposition of thicker films.

Furthermore, we investigated the reactions between the methyl-terminated $\mathrm{Al}_{2} \mathrm{O}_{3}$ surface with $\mathrm{HQ}$ and PD molecules functionalised with activating groups $\left(\mathrm{OCH}_{3}, \mathrm{CH}_{3}\right)$ and deactivating groups $\left(\mathrm{Cl}, \mathrm{NO}_{2}\right)$ to examine the influence of phenyl functionalization on the interaction between the $\mathrm{O}$ and $\mathrm{N}$ site of the aromatic molecule and the Al site of TMA. We found that functionalization can promote the HQ molecule in a more upright configuration and does not weaken the existing Al-O bond. For the PD 
molecule, calculations showed that the functionalization of the molecule can impact the chemistry of the $\mathrm{NH}_{2}$ group with TMA by increasing the interactions between the precursors. So, we can modify the core of the molecule to target particular properties while promoting the deposition of thicker and thereby more flexible Al-organic films.

We also analyzed the interactions between the methyl-terminated $\mathrm{Al}_{2} \mathrm{O}_{3}$ surface and the new possible MLD organic precursors as hydroquinone bis(2-hydroxyethyl)ether and 1,1'-biphenyl-4,4'-diamine. DFT calculations show that longer molecules have weaker upright interaction energy. This may be because longer organic molecules are prone to lying flat, resulting in less thick films. So also the length of the organic molecule plays a role in the film thickness. However, DFT shows that hydroquinone bis(2-hydroxyethyl)ether would be a suitable component for the MLD process. This study generates important new knowledge in the mechanism of Al-organic film growth and allows us to propose and understand the MLD processes for other hybrid materials.

\section{Acknowledgements}

A.M. acknowledges support from H2020 MSCA-ITN Network HYCOAT, Grant Number 765378. MN acknowledges support from Science Foundation Ireland, through the SFI-NSFC Partnership Program, project NITRALD 17/NSFC/5279. A.M. and M.N. acknowledge support from Science Foundation Ireland for computational resources at Tyndall National Institute.

\section{References}

1 P. Judeinstein and C. Sanchez, Hybrid organic-inorganic materials: a land of multidisciplinarity Chemistry: Synthesis of Hybrid Materials, Journal of Materials Chemistry, 1996, 6(4), 511-525.

2 P. Gomez-Romero, Hybrid Organic-Inorganic Materials-In Search of Synergic Activity, Advanced Materials, 2001, 13(3), 163-174.

3 P. Sundberg and M. Karppinen, Organic and inorganic - organic thin film structures by molecular layer deposition: A review, Beilstein Journal of Nanotechnology, 2014, 5, 1104-1136.

4 K. Gregorczyk and M. Knez, Progress in Materials Science Hybrid nanomaterials through molecular and atomic layer deposition: Top down, bottom up, and in-between approaches to new materials, Progress in Materials Science, 2016, 75, 1-37.

5 X. Meng, An Overview of Molecular Layer Deposition for Organic and Organic-Inorganic, Journal of Materials Chemistry, 2017, 5(35), 1-53.

6 W. A. Zoubi, M. P. Kamil, S. Fatimah, N. Nisa, and Y. G. Ko, Recent advances in hybrid organicinorganic materials with spatial architecture for state-of-the art application, Progress in Materials Science, 2018, 112, 100663.

7 K. Haas, K. Rose and G. Schottner, Functionalized coatings based on inorganic - organic polymers (ORMOCER A s) and their combination with vapour deposited inorganic thin films, Surface and Coatings Technology, 1999, 111(1), 72-79.

8 R. Makote and M. M. Collinson, Template Recognition in Inorganic - Organic Hybrid Films Prepared by the Sol - Gel Process, Chemistry of Materials, 1998, 10, 2440-2445.

9 P. Battioni, E. Cardin, M. Louloudi, B. Schollhorn, G. A. Spyroulias, D. Mansuya and T. G. TrayIor, Metalloporphyrinosilicas: a new class of hybrid organic-inorganic materials acting as selective biomimetic oxidation catalysts, Chemical Communications, 1996, 17, 2037-2038.

10 Z-L. Xiaoa, H.-Zh. Chena, M.-M. Shia, G. Wua, R.-J. Zhoua, Zh.-Sh. Yanga, M. Wanga and B.-Zh. Tang, Preparation and characterization of organic-inorganic hybrid perovskite (C4H9NH3)2CuCl4, Materials Science and Engineering: B, 2005, 117(3), 313-316. 
11 M. Ritala, Atomic layer deposition (ALD): from precursors to thin film structures, Thin Solid Films, 2002, 409(1), 138-146.

12 B. S. Lim, A. Rahtu and R. G. Gordon, Atomic layer deposition of transition metals, Nature Materials, 2003, 2(11), 749-754.

13 S. M. George, Atomic Layer Deposition: An Overview, Chemical Reviews, 2010, 110(1), 111-131.

14 R. W. Johnson, A. Hultqvist and S. F. Bent, A brief review of atomic layer deposition: From fundamentals to applications, Materials Today, 2014, 17(5), 236-246.

15 B. H. Lee, B. Yoon, A. I. Abdulagatov, R. A. Hall and S. M. George, Growth and Properties of Hybrid Organic Inorganic Metalcone Films Using Molecular Layer Deposition Techniques, Advanced Functional Materials, 2012, 23(5), 532-546.

16 D. M. King, X. Liang and A. W. Weimer, Functionalization of fine particles using atomic and molecular layer deposition, Powder Technology, 2012, 221, 13-25.

17 X. Liang, M. Yu, J. Li, Y. Jiang and A. W. Weimer, Ultra-thin microporous - mesoporous metal oxide films prepared by molecular layer deposition (MLD), Chemical Communications, 2009, 46, $7140-7142$.

18 J. S. D. Peñaranda, M. Nisula, S. S. T. Vandenbroucke, M. Minjauw,a J. Li, A. Werbrouck, J. Keukelier, A. I. Pitillas Martínez, J. Dendooven and Ch. Detaverniera, Converting molecular layer deposited alucone films into A12O3/alucone hybrid multilayers by plasma densification, Dalton Transactions, 2021,50, 1224-1232.

19 B. H. Lee, V. R. Anderson and S. M. George, Metalcone and Metalcone/Metal Oxide Alloys Grown Using Atomic and Molecular Layer Deposition, Journal of the Electrochemical Society, 2011, 41(2), $131-138$.

20 C. Ban and S. M. George, Molecular Layer Deposition for Surface Modification of Lithium-Ion Battery Electrodes, Advanced Materials Interfaces, 2016, 3(21), 1600762.

21 A. A. Dameron, D. Seghete, B. B. Burton, S. D. Davidson, A. S. Cavanagh, J. A. Bertrand and S. M. George, Molecular layer deposition of alucone polymer films using trimethylaluminum and ethylene glycol, Chemistry of Materials, 2008, 20 , 3315-3326.

22 W. Zhou, J. Leem, I. Park, Y. Li, Z. Jin and Y.-S. Min, Charge trapping behavior in organicinorganic alloy films grown by molecular layer deposition from trimethylaluminum, $p$ phenylenediamine and water, Journal of Materials Chemistry, 2012, 22, 23935-23943.

23 Y-S. Park, H. Kim, B. Cho, C. Lee, S.-E. Choi, M. M. Sung and J. S. Lee, Intramolecular and Intermolecular Interactions in Hybrid Organic-Inorganic Alucone Films Grown by Molecular Layer Deposition, ACS Applied Materials \& Interfaces, 2016, 8, 17489-17498.

24 B. Yoon, J. L. O'Patchen, D. Seghete, A. S. Cavanagh and S. M. George, Molecular layer deposition of hybrid organic-inorganic polymer films using diethylzinc and ethylene glycol, Chemical Vapor Deposition, 2009, 15 , 112-121.

25 Q. Peng, B. Gong, R. M. VanGundy and G. N. Parsons, "Zincone" zinc oxide-organic hybrid polymer thin films formed by molecular layer deposition, Chemistry of Materials, 2009, 21, 820-830.

26 B. Yoon, Y. Lee, A. Derk, C. Musgrave and S. George, Molecular layer deposition of conductive hybrid organic-inorganic thin films using diethylzinc and hydroquinone, ECS Transactions, 2011, 33 , 191-195.

27 A. I. Abdulagatov, R. A. Hall, J. L. Sutherland, B. H. Lee, A. S. Cavanagh and S. M. George, Molecular layer deposition of titanicone films using $\mathrm{TiCl}_{4}$ and ethylene glycol or glycerol: growth and properties, Chemistry of Materials, 2012, 24, 2854-2863. 
28 Y.Q. Cao, L. Zhu, X. Li, Z.-Y. Cao, D. Wu and A.-D. Li, Growth characteristics of Ti-based fumaric acid hybrid thin films by molecular layer deposition, Dalton Transaction, 2015, 44 , 14782 14792

29 K. Van de Kerckhove, F. Mattelaer, D. Deduytsche, P. M. Vereecken, J. Dendooven and C. Detavernier, Molecular layer deposition of "titanicone", a titanium-based hybrid material, as an electrode for lithium-ion batteries, Dalton Transaction, 2016, 45 , 1176-1184

30 B. H. Lee, V. R. Anderson and S. M. George, Growth and properties of hafnicone and $\mathrm{HfO}_{2} /$ hafnicone nanolaminate and alloy films using molecular layer deposition techniques, $A C S$ Applied Materials \& Interfaces, 2014, 6, 16880-16887

31 K. Van de Kerckhove, F. Mattelaer, J. Dendooven and C. Detavernier, Molecular layer deposition of "vanadicone", a vanadium-based hybrid material, as an electrode for lithium-ion batteries, Dalton Transaction, 2017, 46 , 4542-4553

32 J. Kint, F. Mattelaer, S. S. T. Vandenbroucke, A. Muriqi, M. M. Minjauw, M. Nisula, Ph. M. Vereecken, M. Nolan, J. Dendooven, and Ch. Detavernier "Molecular Layer Deposition of "Magnesicone", a Magnesium-based Hybrid Material", Chemistry of Materials, 2020 32(11), 44514466.

33 B. H. Lee, M. K. Ryu, S.-Y. Choi, K.-H. Lee, S. Im and M. M. Sung, Rapid vapor-phase fabrication of organic-inorganic hybrid superlattices with monolayer precision, Journal of the American Chemical Society, 2007, 129, 16034-16041

34 B. H. Lee, K. H. Lee, S. Im and M. M. Sung, Vapor-phase molecular layer deposition of selfassembled multilayers for organic thin-film transistor, J. Nanosci. Nanotechnol, 2009, 9, 6962-6967

35 L. Keskivali, M. Putkonen, E. Puhakka, E. Kentta, J. Kint, R. K. Ramachandran, Ch. Detavernier and P. Simell, Molecular Layer Deposition Using Ring-Opening Reactions: Molecular Modeling of the Film Growth and the Effects of Hydrogen Peroxide, ACS Omega, 2018, 3(7), 7141-7149.

36 F. Yang, J. Brede, H. Ablat, M. Abadia, L. Zhang, C. Rogero, S. D. Elliott and M. Knez, Reversible and Irreversible Reactions of Trimethylaluminum with Common Organic Functional Groups as a Model for Molecular Layer Deposition and Vapor Phase Infiltration, Advanced Materials Interfaces, 2017, 4(18), 170-237.

37 A. Muriqi and M. Nolan, First principles study of reactions in alucone growth: the role of the organic precursor, Dalton Transaction, 2020, 49, 8710-8721

38 K. Van De Kerckhove, M. K. S. Barr, L. Santinacci, Ph. M. Vereecken, J. Dendooven and C. Detavernier, The transformation behaviour of 'alucones', deposited by molecular layer deposition, in nanoporous A12O3 layers, Dalton Transaction, 2018, 47 , 5860-5870

39 K. Van De Kerckhove, J. Dendooven and C. Detavernier, Annealing of thin "Tincone" films, a tin-based hybrid material deposited by molecular layer deposition, in reducing, inert, and oxidizing atmospheres, Journal of Vacuum Science \& Technology A, 2018, 36 , 51-506

40 J. Multia, A. Khayyami, J. Heiska and M. Karppinen, Low-pressure thermogravimetric analysis for finding sublimation temperatures for organic precursors in ALD/MLD, Journal of Vacuum Science \& Technology A, 2020, 38, 052406.

41 K. B. Klepper, O. Nilsen, H. Fjellvag, Deposition of Thin, Films of Organic-Inorganic Hybrid Materials Based on Aromatic Carboxylic Acids by Atomic Layer Deposition. Dalton Transaction, 2010, 39, 11628-11635.

42 B. Yoon, B. H. Lee, S. M. George, Highly Conductive and Transparent Hybrid Organic-Inorganic Zincone Thin Films Using Atomic and Molecular Layer Deposition, The Journal of Physical Chemistry A, 2012, 116, 24784-24791. 
43 T. Tynell, I. Terasaki, H. Yamauchi, M. Karppinen, Thermoelectric Characteristics of (Zn,Al)O/Hydroquinone Superlattices, Journal of Materials Chemistry A, 2013, 1, 13619-13624.

44 P. Sundberg, M. Karppinen, Organic and Inorganic-Organic Thin Film Structures by Molecular Layer Deposition: A Review, Beilstein Journal of Nanotechnology, 2014, 5, 1104-1136.

45 E. Ahvenniemi, M. Karppinen, Atomic/Molecular Layer Deposition: A Direct Gas-Phase Route to Crystalline Metal-Organic Framework Thin Films. Chemical Communications, 2016, 52, 1139-1142.

46 M. Nisula, J. Linnera, A. J. Karttunen, M. Karppinen, Lithium Aryloxide Thin Films with GuestInduced Structural Transformation by ALD/MLD, Chemistry A European Journal, 2017, 23, 2988 2992.

47 D. J. Hagen, L. Mai, A. Devi, J. Sainio, M. Karppinen, Atomic/Molecular Layer Deposition of CuOrganic Thin Films. Dalton Transactions, 2018, 47, 15791- 15800

48 A. Sood, P. Sundberg, J. Malm and M. Karppinen, Layer-by-layer deposition of Ti-4,4'-oxydianiline hybrid thin films, Applied Surface Science. 2011, 257, 6435- 6439.

49. K.B. Klepper, O. Nilsen, T. Levy and H. Fjellvåg, Atomic Layer Deposition of Organic-Inorganic Hybrid Materials Based on Unsaturated Linear Carboxylic Acids, European Journal of Inorganic Chemistry, 2011, 34, 5305-5312.

50 J. Heiska, O. Sorsa, T. Kallio and M. Karppinen, Benzenedisulfonic acid as a new ALD/MLD building block for crystalline metal-organic thin films, Chemistry - A European Journal, 2021, 27, 8799-8803.

51 G. Kresse and J. Furthmu, Efficient iterative schemes for ab initio total-energy calculations using a plane-wave basis set, Physical Review. B, 1996, 54, 11169-11186.

52 P. Blochl Projector augmented-wave method, Physical Review B, 1994, 50, 17953

53 J. P. Perdew, K. Burke and M. Ernzerhof, Generalized gradient approximation made simple, Physical Review Letters, 1996, 77, 3865

54 G. R. Jenness, J. Seiter and M. K. Shukla, DFT investigation on the adsorption of munition compounds on $\alpha-\mathrm{Fe} 2 \mathrm{O} 3$ : similarity and differences with $\alpha-\mathrm{A} 12 \mathrm{O} 3$, Physical Chemistry Chemical Physics, 2018, $20,18850-18861$

55 A.Tanskanen, P. Sundberg, M. Nolan and M. Karppinen, Atomic/molecular layer deposition of Tiorganic thin films from different aromatic alcohol and amine precursors, Thin Solid Films, 2021, 736, 138896.

56 J. Multia, J. Heiska, A. Khayyami and M. Karppinen, Electrochemically active in-situ crystalline lithium-organic thin films by ALD/MLD, ACS Applied Materials \& Interfaces, 2020, 12, 41557-41566. 